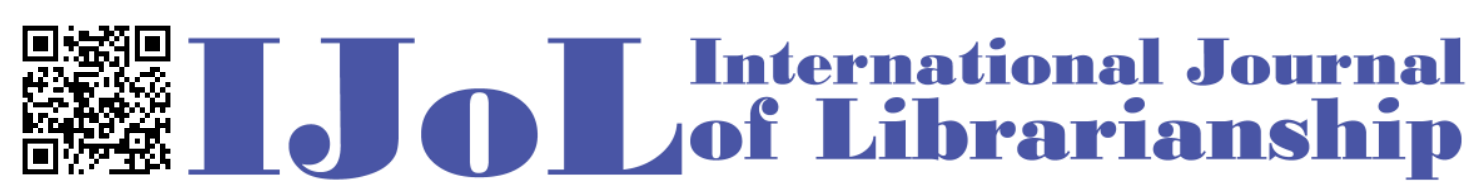

ISSN: 2474-3542 Journal homepage: http://journal.calaijol.org

\title{
Teaching a Cataloging/Metadata Course in a Changing World: Experience and Reflection
}

\author{
Suzhen Chen and Margaret Joyce
}

\begin{abstract}
:
In this paper, we explore the most essential knowledge and skills to impart in an introductory-level cataloging and metadata course. We use the basic cataloging and metadata class in the University of Hawai'i at Mānoa Library and Information Science Program as a case study, sharing our experiences, thoughts, and planned future direction in teaching cataloging, classification, metadata, and information organization. We investigate what University of Hawai'i at Mānoa Library and Information Science (LIS) students expect to learn from the class, as well as how they perceive knowledge of and skills in cataloging and metadata affecting their career paths. We also inquire into topics that the students are interested in exploring related to cataloging and metadata. We examine emerging trends and evaluate which information and skills are most useful for LIS students and new librarians to learn for their library careers. These ideas are built upon our own experiences teaching these topics. This article synthesizes literature review, observation of trends within cataloging and metadata, and surveys taken by students enrolled in the course.
\end{abstract}

To cite this article:

Chen, S. \& Joyce, M. (2019). Teaching a cataloging/metadata course in a changing world: Experience and reflection. International Journal of Librarianship, 4(2), 111-122.

To submit your article to this journal:

Go to http://ojs.calaijol.org/index.php/ijol/about/submissions 


\title{
Teaching a Cataloging/Metadata Course in a Changing World: Experience and Reflection
}

\author{
Suzhen Chen, Margaret Joyce \\ University of Hawaii at Manoa, Honolulu, Hawaii, USA
}

\begin{abstract}
In this paper, we explore the most essential knowledge and skills to impart in an introductory-level cataloging and metadata course. We use the basic cataloging and metadata class in the University of Hawai'i at Mānoa Library and Information Science Program as a case study, sharing our experiences, thoughts, and planned future direction in teaching cataloging, classification, metadata, and information organization. We investigate what University of Hawai'i at Mānoa Library and Information Science (LIS) students expect to learn from the class, as well as how they perceive knowledge of and skills in cataloging and metadata affecting their career paths. We also inquire into topics that the students are interested in exploring related to cataloging and metadata. We examine emerging trends and evaluate which information and skills are most useful for LIS students and new librarians to learn for their library careers. These ideas are built upon our own experiences teaching these topics. This article synthesizes literature review, observation of trends within cataloging and metadata, and surveys taken by students enrolled in the course.
\end{abstract}

Keywords: Cataloging, Metadata, Information Organization, Library, Library and Information Science, Student, Pedagogy, Inquiry-Based Learning, Motivation

\section{INTRODUCTION}

Cataloging and metadata skills are fundamental aspects of the organization of knowledge and information. Metadata is used to facilitate discovery, retrieval, and interoperability in a variety of contexts, such as library catalogs (traditional cataloging), digital repositories, databases, and web platforms. To ground ourselves in current thought on the topics of the utility of metadata management courses and the manner of instruction in these courses, we will review recent literature related to the teaching of cataloging and metadata.

Literature within the field shows that knowledge and skills related to cataloging, classification, metadata management, and information organization are among the core skills of librarianship. ALA's Core Competences of Librarianship includes knowledge of "the systems of cataloging, metadata, indexing, and classification standards and methods used to organize recorded knowledge and information" (ALA's Core Competences of Librarianship, 2009). Many cataloging/metadata professionals have emphasized the importance of these skills in information 
organization. In 2002, Gorman stated that cataloging is the "intellectual foundation of librarianship" (p. 11). This was echoed by Hsieh-Yee (2002), who highlighted the ways in which a firm grasp of the theory of cataloging, subject analysis, thesaurus, and classification, etc. would aid professional librarians. Carlyle equated understanding cataloging with understanding library resources (Dull, 2011). Olson (1997) stressed the need to understand catalogs and integrated library systems in a "holistic manner" (p. 52), meaning that the cataloger or cataloging instructor must focus not only on standards, but also on the reasoning behind such standards and the way that their adoption would affect both the library community and the user. In other words, we don't only need to learn and teach the how of cataloging, but also the why: the way in which these rules relate to other library functions. Indeed, Gorman (2002) asserts the need for a reference librarian to understand the criteria used for description in selecting resources as well as for an instruction librarian to understand the structure of the catalog when advising on search strategies to use with it. Standards are created so that the catalog "can effectively perform its mediating function between the collection and the users" (Olson, 1997, p. 52), which is part of the goal of all library services. Metadata consistency is important for collocating information and enhancing data exchange in automated computerized environments locally, nationally, and internationally. Rousidis et al. (2015) stated that 21 variations were used for fertilization when no controlled vocabulary was used in their project to perform a descriptive analysis of the DC (Dublin Core) subject metadata element in a repository. The inconsistent use of the data inadvertently affected data processing. This shows some of the ways standardization in cataloging and metadata matters in information retrieval and information sharing. This strengthens the argument that a basic understanding of cataloging and metadata practices will benefit librarians who follow a variety of career paths.

The applicability of metadata skills has only increased in the digital world. Joudrey and McGinnis (2014) opined that "whether they intend to work in cataloging or not, students will need a conceptual grounding in metadata concepts to navigate the changing graduate education for information organization, cataloging, and metadata" (p. 515). Well-applied and understood metadata enhances discoverability for a variety of library collections and is a driving force in building useable digital collections (Saumure \& Shiri, 2008). If LIS graduates become more capable of applying whatever standards are proper to manage and organize information within and outside libraries, information will be better classified and users will be able to find and access information in the networked environment easier and faster (Hsieh-Lee, 2004). Saumure \& Shiri (2008) stated that the importance of metadata in these knowledge organization domains may be the reason that "has led knowledge organization educators to point out the utility and necessity of teaching students about metadata" (p. 660).

These examples show that the importance of cataloging and metadata in information organization is evident to those who deal with metadata. However, new LIS students may not be aware of the importance of these skills. This is especially true as more and more LIS programs do not consider cataloging and metadata a core course, according to a 2016 study (Alajmi \& ur Rehman). 


\section{ADDRESSING THE CURRENT METADATA LANDSCAPE}

Metadata professionals know how important it is to stay abreast of changes in the field. Over the last several years, there have been many new standards and practices that have required additional training and adjustments to cataloging workflows. In that time, catalogers have started "organizing information by looking at entities, attributes, and relationships in an "FRBR-ized" world" (Joudrey \& McGinnis, 2014, p. 508). There was the wide adoption of RDA (Resource Description \& Access) standard based on the FRBR (Functional Requirements for Bibliographic Records) model, which is a framework established by the International Federation of Library Associations and Institutions (IFLA) to aid in the understanding and development of standards for bibliographic description (IFLA Study Group, 1998). We now look towards a revised RDA content standard following the LRM (Library Reference Model), a high-level conceptual reference model developed by IFLA within an entity-relationship modeling framework (Riva et al., 2017). These changes represent shifting structures and models in metadata that even the most experienced librarian needs time to absorb. MARC cataloging has been proclaimed obsolete for many years, and yet it remains the main schema for metadata used in integrated library systems (Cole, Han, \& Schwartz, 2018). Metadata and cataloging professionals have seen many projects using BIBFRAME (Bibliographic Framework) and linked data described as the future of cataloging. Standards such as RDF (Resource Description Framework), a framework for describing web resources, and SPARQL (SPARQL Protocol and RDF Query Language), an RDF query language, are used in these linked data environments. These new tools have been discussed, tested, and utilized in the library community.

We have seen the role of metadata gain importance as ontologies and taxonomies are also playing a crucial role in the semantic web. The expansion of "linked-data vocabularies has been motivated by new technology and the promise of new means for sharing knowledge" (Moulaison et al., 2012, p. 2). The organization of information continues to evolve, though modules on subjects such as taxonomies, ontologies, and thesauri are not heavily emphasized in the LIS schools' courses (Alajmi \& Ur Rehman, 2016), which can leave students unaware of the importance of metadata skills. As more resources move to the interconnected web, emerging topics such as metadata applications and uses in the open web, ontologies, and classifying web resources will receive more attention. Omekwu \& Eteng (2006) state that information professionals need new skill sets to perform new information service roles. Future librarians will need to incorporate these realities into new or redefined roles for information organization professionals. Though the nature of our work and the tools we use to do it may change, the fundamental purpose of our work does not. This, then, is what we must instill in new library professionals.

Changes and the scope of relevant projects and schemas do provide a challenge for LIS educators. We cannot ensure that the standards we teach our students will be the ones they continue to use throughout their career. We must accept that "change is inevitable for organizational survival and the maintenance of professional relevance" (Omekwu \& Eteng, 2006, p. 267). While ideally, the students would have time to adjust to current standards before new ones are introduced, in some ways prospective changes will prepare the students for careers in the library field, which is always evolving. 


\section{STUDENT SURVEYS}

In order to gauge the knowledge of incoming and outgoing students in the cataloging and metadata class, we, as cataloging instructors in the UHM LIS program, constructed a two-part survey. The intent of the first part of the survey was to gather information on the students' background knowledge of cataloging and metadata skills, why they took the class, and what they expected to learn from the course. The second part of the survey, administered at the end of the course, was used to solicit student opinions on the most valuable aspects of the course. We used the information gathered to learn more about the students, their experiences, and to inspire improvements to the course.

Surveys were given over multiple semesters at the beginning of the term from 2016 to 2019 , to 48 students overall, with 46 responses returned. In the survey, multiple questions were asked, among which were "What is your knowledge/experience with cataloging and metadata?" (Q1), "What do you expect to learn from this course?" (Q2), and "What is your main reason for taking this course?" (Q3).

When asked about their background with cataloging and metadata, about 54\% (25 out of 46) of the students stated that they did not have knowledge of/experience with cataloging and metadata creation. About $46 \%$ (21 out of 46) of students indicated that they had very limited or minimum knowledge of/experience with metadata creation. For Q3, why they chose to take the course, about $61 \%$ (28 out of 46 ) of students stated that they took the course because it was a required/core course. $65 \%$ (30 out of 46) of the surveyed students expressed their awareness of the importance of the course and a desire to learn about the topics covered.

Selected responses for $Q 2$ as to what the students expected to learn from the class

"This required course will provide me with the important and fundamental skills I will need to be a good school librarian."

"To learn more about cataloging and metadata creation will help me in my professional career."

"Need it for cataloging \& metadata skill."

"To learn how to actually catalog."

"Learn more about cataloging \& metadata creation. Interested in becoming a digital librarian, so will be helpful."

From the survey, we learned that most students who took the class had no or minimal knowledge of cataloging and metadata. Among the $61 \%$ of students who indicated that they took 
the class because it was required, only a small percentage added language about the importance of knowledge and skills of cataloging and metadata. This suggests that as more LIS schools do not require basic cataloging and metadata, library and information science students will choose not to take the class. This could create a discrepancy between the knowledge and skills needed by LIS students as future librarians/information specialists in many settings and the education that they receive in library school.

At the end of the course each semester, follow-up questions were asked in part two of the survey. One of the questions was "Which aspects of the course were most valuable?" Below is a selection of the students' feedback to the question.

\section{Acquire cataloging skills}

- Gain cataloging experience

- Learn how bibliographic records are created

- Learn from hands-on examples

\section{Gain knowledge of different tools and resources}

- Use cataloging and classification tools

- Become familiar with metadata creation resources

\section{Learn the basics of metadata and cataloging}

- Learning the inner workings of record creation

- Practicing different organizational techniques

- Knowing more about the unseen parts of librarian work

- Helpful for the future as a librarian

Even though some students do not initially realize the importance of the introductory-level cataloging and metadata class, many subsequently discover the value of understanding cataloging, classification, and metadata. As seen above, the practical aspects of the course were particularly well received, as students learned to both understand existing records and create their own using the same tools as professionals in the field (OCLC Connexion, RDA toolkit, ClassWeb). Much of the class discussion, though, focused on the "why" of certain rules and the way that the structures of traditional cataloging influence the cataloging of resources, as the students sought to link philosophy and practice.

\section{Course content and goals}

As adjunct instructors, as well as practicing catalogers at a public co-educational research university, it is of paramount importance for us, the LIS instructors, to help the students to acquire knowledge and skills to prepare for their careers in librarianship.

In order to accomplish this goal, we feel that it is not enough to only teach traditional cataloging skills; we must also incorporate new developments in the field. This is a significant challenge since the course schedule is already rigorous, allowing only enough time to give students 
a grounding in key aspects of cataloging and metadata management. How, then, can we prepare students to encounter metadata in a variety of contexts, while also providing them with knowledge of and perspective on different aspects of bibliographic data in the library environment? The field of cataloging, metadata, and information organization is changing constantly, and there are many topics to cover. As instructors for a LIS class, we cannot incorporate all relevant aspects into the 16-week introductory-level cataloging/metadata class. Therefore, we use a variety of strategies and teaching methods to improve student learning outcomes and encourage students to not only learn the rules, but to think about how those rules were constructed and what purposes they serve:

\section{Promote student learning.}

Pedagogy, the art, occupation, or practice of teaching, is a topic of interest to educators. Pedagogy encompasses theory and a method of teaching based on such a theory (Oxford English Dictionary, 2019). The content of the introductory-level cataloging and metadata course requires reflective thinking and inquiring learning skills rather than pure memorization of factual knowledge. Basic knowledge of a cataloging standard, metadata scheme, thesaurus, and classification system can be transferable to learning other standards, thesauri, controlled vocabularies, etc. only if the students understand the underlying structure that is common to those standards. The most important skill for practical cataloging, then, is not knowing what the rule in a particular situation is by rote, but instead, being familiar enough with cataloging resources to select the right one to use to find the information you need. This relates to a central tenet of librarianship, that we need not always be an expert in every topic, but that our training provides us with the skills necessary to find the answers.

Recognizing the importance of an introduction to cataloging and metadata class for all library students means that instructors must also recognize that most of the students in the class will not go on to be catalogers. How, then, can we motivate students to think about the tools that cataloging offers them, such as classification, description, and subject analysis? Jerome Bruner, an American educational psychologist, strongly supports discovery learning. As a constructivist, he believes that learning does not only involve mastery of the contents, but also an attitude toward learning and inquiry and the ability to solve problems on one's own (Boettcher, 2010). Motivating students is essential to achieve better student learning outcomes. In the class, we have found it more effective to provide opportunities for students to explore the metadata topics related to their own interests, rather than to instill in them extensive knowledge of cataloging and metadata rules and standards. In the past two years, we have provided students with more opportunities to select their own topics, lead class discussions, and share ideas both online and in class. This has resulted in the students being more engaged in class, as they can relate the material to their intended career path.

Connecting classroom work with topics that the students see impacting their future roles as librarians has been one of our goals in adjusting coursework. In addition to requiring the students to create MARC records that cover description, subject analysis and classification, students are also required to give a final presentation on a topic of their choice related to cataloging and metadata. These short presentations mirror the kinds of presentations given at professional conferences and provide the students with an opportunity to do research and present findings. The presentations also give students the chance to talk about the cataloging of different formats and subjects, inadequacies and issues with current vocabularies, and a variety of metadata standards. These presentations build on the work of the previous weeks, allowing students to compare 
standards and think critically about the ways that cataloging and metadata impact access and discovery. Being able to compare standards and not differences is one demonstrable way to show an understanding of both the practical and the philosophical aspects of metadata application.

In order to get to know what topics students are interested in exploring, we collect some topics that the students have researched, presented, and discussed during past classes. Here is a selection of the topics.

Cataloging for specific languages, formats, and subjects

- Cataloging graphic materials

- Music cataloging

- Cataloging realia

- Cataloging rare books

- Cataloging children's books

- Classification for the classics

- Cataloging magazines and newspapers

- Cataloging non-Roman script resources

- Cataloging graphic music

\section{Metadata in other contexts}

- Cataloging and metadata for archival collections

- Cataloging couture

- Cataloging materials in museums

- Folksonomies and social tagging

- Semantic networks for information

- Metaloging geospatial data

- Linked data

\section{Critical thinking about cataloging and metadata}

- Critique of the catalog

- Cooperative cataloging

- Criticism of LGBTQ classification and subject headings

- Cataloging on a global scale

- User-centered classification

- Ethical issues in cataloging

- Indigenous knowledge organization including Hawaiian knowledge organization systems

From the topics, we learn that students' interests within the field vary significantly. The topics cover not only the practical concerns of cataloging library material for different subjects, languages, and formats, but also expand to think of some of the broader applications of metadata. In the presentation the students have the opportunity to address their concerns, whether it be investigating the "how" of the ways that different aspects of works are represented within the 
MARC format, or asking "why" questions about how information can be adapted, reevaluated, and made more inclusive. Through their choice and exploration of a topic, the individual student has more opportunity to initiate their own learning and apply the skills and topics covered in class to their particular concerns.

Another way that we have encouraged students to find material related to cataloging and metadata relevant to their interests is by replacing the previously required short essay on a peerreviewed article with leading a class discussion on such an article. In this case, the student who read the article has to think more carefully about how to explain the content to their classmates and come up with questions to facilitate discussions that involve the class as a whole. Knowing that they will be sharing their work with their classmates and formulating questions also makes the students more likely to pick topics that speak to them. While including additional class discussion does take up time in an already compressed class schedule, the time is well spent in getting students to consider multiple aspects of cataloging and metadata in information organization and bringing real-world examples from multiple perspectives into the classroom. Though we have only recently introduced this aspect of student-led discussion to the course, it has been quite valuable in allowing students to express their interests and relate them to the material covered, while also engaging the students with each other when discussing cataloging and metadata related topics. This direction emphasizes the need to leave students not only understanding the rules and practical applications of providing good metadata, but also recognizing the important role it can play in many aspects of librarianship. We hope that through taking the class, the students will be able to identify the ways that metadata can aid or hinder their work and understand how the frameworks of controlled vocabularies, classification schemes, and metadata elements impact the interaction between librarians, patrons, and resources.

In the future, there will be a need to continue to promote students' learning through pedagogy, learning outcomes, and assessment, and to continue to motivate the students to achieve through their work, involvement, and participation in the course.

2. Balance theory and practice in the course.

According to the Oxford English Dictionary, a theory is the conceptual fundamentals of a subject or area of study (Oxford English Dictionary, 2019). Theorizing and conceptualizing information are the practices of establishing the phenomenon of study for a discipline and refining the phenomenon studied by the discipline; they are essential analytic practices for establishing a discipline (Carlin, 2009). On the other hand, learning theory is a way and process of understanding a discipline. In the profession of librarianship, technology is changing constantly. Rules in cataloging and metadata are changing as well. The basic knowledge of theory such as cataloging, authority control, subject headings, and thesaurus will be helpful for students to apply the fundamentals of cataloging to the organization of information resources in all kinds of formats (Hsieh-Yee, 2010).

One of the many challenges in an introduction to cataloging and metadata class is striking the right balance between theory and the very practical rules involved in creating standardized metadata. Should instructors focus on preparing students to create records or helping students understand the organizational principles behind current practices? This conundrum mirrors the larger one in LIS instruction: wanting our students to be prepared both to do practical library work and to think critically about the underlying aspects of the profession. As in many situations, we have found that the most valuable thing might be to have a bit of both. 
Regarding theory, the course outcomes are achieved through lectures, readings, and discussions relating to the concerns current cataloging practice was created to address. In this way, students learn the structures common to a variety of metadata standards and leave the class able to identify issues with the application of metadata practices in various settings. Though we cannot give comprehensive focus to the different areas of metadata skill, giving space to talk about the theory and evolution of knowledge organization helps the students to think critically about the current issues in cataloging and metadata in information organization.

The class provides hands-on experience through the quizzes covering different aspects of cataloging. These topics converge in the students' final project: the creation of five complete metadata records that allow them to synthesize their understanding of description, subject analysis, and classification. In order to give the students practical experiences in metadata creation in a broader context, we also collaborated with the CALA (Chinese American Librarians Association) Academic Resource \& Repository System (CALASYS), getting the students involved in hands-on metadata experience through the CALA institutional repository, which stores materials and documents including publications, research, reports, and datasets. The students create metadata records for the institutional repository, utilizing the skills they have learned throughout the course.

3. Balance traditional cataloging knowledge and skills in library settings and metadata in the semantic web.

There is an increasing awareness that library users and information seekers become more self-sufficient and move beyond library collections in the pursuit of information in today's "technology-driven research, teaching, and learning environments" (Calhoun, 2007, p. 7). Metadata plays an essential role not only in managing library resources, but also in organizing and classifying many types of web resources. In order to provide better information services, libraries have been interested in creating and displaying many other types of metadata besides descriptive cataloging, including "rights, technical, structural, administrative, evaluative, preservation, and linking metadata" (Calhoun, 2007, p. 18). In addition to introducing different types of metadata to LIS students, LIS instructors should also prepare students to "identify areas for metadata development, application, and evaluation" (Hsieh-Lee, 2004, p. 66). LIS students need to learn skills that are applicable beyond the traditional library-cataloging environment. Accordingly, course content should address new developments in the interconnected worldwide computer network and enable students to grasp the fundamentals of metadata for digital objects, special collections, and other resources that will be accessible online and linked to one another.

The skills and knowledge needed in a library career are evolving. The teaching of cataloging and metadata also needs to change and adapt to suit emerging trends and changes in users' information seeking behaviors. In recent years, new concepts and new standards have been introduced. New models have been developed, tested, and utilized. As more resources move to the semantic web, linked data becomes an increasingly engaging topic in the field. In the linked data environment, data can be linked to other data located on the web (Berners-Lee, 2006).

In the future, new networked architecture and content management systems will be developed. LIS educators for information organization should watch the latest trends and developments. As more web resources are moving to the interconnected web, emerging topics including metadata applications and uses in the open web, ontologies, and classifying web resources will receive more attention. During the past few years, we have gradually introduced different types of metadata schemas and metadata standards, metadata creation tools, and resources 
including linked data into the course. In addition, the students have had the opportunity to work with the web publishing tool Omeka and create metadata records in a real-world situation. The class project will help the students have a better understanding of metadata creation in the digital environment.

We will regularly revisit the syllabus and course content and incorporate emerging trends in the field.

\section{SUMMARY}

Based on the survey results from the UHM LIS students who took the introductory-level cataloging and metadata class, most LIS students had no background and minimum knowledge or skills in cataloging and metadata before they took the class. The basic cataloging/metadata class helped them to gain knowledge and skills in the area and to understand that metadata plays an important role in digital scholarship. We feel it is essential to combine the traditional cataloging/metadata skills with a focus on emerging trends in the field to prepare students for their future careers. "Metadata is an evolving area of information organization that is constantly in flux and the technologies used to support its teaching and implementation are changing just as rapidly" (HsiehYee, 2006, p. 2). Changes and innovation must drive not only the course content, but also the instructors' pedagogical approach, as the instructors need to inspire the students to pursue inquirybased learning. As the metadata landscape changes, it is necessary for us, the instructors, to continue to evaluate the course content, our pedagogy, and student learning outcomes.

Over the past few years, as instructors for the cataloging and metadata course, we have been focusing primarily on the skills necessary for cataloging in the traditional library-focused environment, but have incorporated new content to address broader issues and a wider variety of tools and situations in which metadata, and the knowledge of how to create and follow appropriate standards, is valuable. Methods involved in teaching the cataloging and metadata course need to evolve as the nature of information seeking changes. There is a need to incorporate new concepts and developments related to rapidly changing digital technology while staying true to the essence of "traditional" cataloging and classification in the library setting. On the one hand, we acknowledge that topics such as classification, cataloging, and indexing form the backbone of knowledge organization education (Alajmi \& Ur Rehman, 2016); on the other hand, we understand that to remain relevant, LIS instructors must take the opportunity to learn and equip ourselves with updated knowledge and skills in the field. This will allow us to incorporate new developments in the curriculum to reflect the changes in the information world and provide useful and enriching experiences for the students, no matter their experience or focus.

\section{References}

ALA Council. (2009). ALA's core competencies of librarianship. Retrieved from http://www.ala.org/educationcareers/sites/ala.org.educationcareers/files/content/careers/cor ecomp/corecompetences/finalcorecompstat09.pdf

Alajmi, B., \& ur Rehman, S. (2016). Knowledge organization trends in library and information education: assessment and analysis. Education for Information, 32(4), 411-420. https://doi.org/10.3233/EFI-160084 
Berners-Lee, T. (2006, July 27). Linked data. Retrieved from https://www.w3.org/DesignIssues/LinkedData.html

Boettcher, J. V. (2010). The online teaching survival guide: simple and practical pedagogical tips (1st ed.). San Francisco: Jossey-Bass.

Calhoun, K. (2007). Being a librarian: metadata and metadata specialists in the twenty-first century. Library Hi Tech, 25(2), 174-187. https://doi.org/10.1108/07378830710754947

Carlin, A. (2009). Segmented professions: further considerations of theory and practice in LIS and librarianship. Library Philosophy and Practice, 294. Retrieved from http://digitalcommons.unl.edu/libphilprac/294

Cole, T. W., Han, M. K., \& Schwartz, C. (2018). Coding with XML for efficiencies in cataloging and metadata: practical applications of XSD, XSLT, and XQuery. Chicago: ALA Editions.

Dull, M. E. (2011). Cataloging education and cataloging futures: an interview with Allyson Carlyle. Serials Review, 37(2), 116-119.

Gorman, M. (2002). Why teach cataloguing and classification? Cataloging \& Classification Quarterly, 34(1-2), 1-13.

Hsieh-Yee, I. (2002). Cataloging and metadata education: asserting a central role in information organization. Cataloging \& Classification Quarterly, 34(1-2), 201-220.

http://doi.org/10.1300/J104v34n01_12

Hsieh-Lee, I. (2004). Cataloging and metadata education in North American LIS programs. Library Resources \& Technical Services, 48(1), 59-68.

Hsieh-Yee, I., Vellucci, S., Moen, W. E., Miksa, F., \& Hillmann, D. I. (2006). Building a digital teaching commons to enhance teaching, learning and research: the MERIC experience and challenges. Proceedings of the American Society for Information Science and Technology, 43(1), 1-7. Retrieved from https://asistdl.onlinelibrary.wiley.com/doi/full/10.1002/meet.14504301101

IFLA Study Group. (1998). Functional requirements for bibliographic records, final report. Retrieved from https://www.ifla.org/files/assets/cataloguing/frbr/frbr_2008.pdf

Joudrey, D. N., \& McGinnis, R. (2014). Graduate education for information organization, cataloging, and metadata. Cataloging \& Classification Quarterly, 52(5), 506-550. https://doi.org/10.1080/01639374.2014.911236

Moulaison, H. L., Rathbun-Grubb, S., Abbas, J., Greenberg, J., La Barre, K., Rodríguez, E. M., ... Šauper, A. (2012). Emerging trends in metadata research. Proceedings of the American Society for Information Science and Technology, 49(1), 1-4. https://doi.org/10.1002/meet.14504901174 
Olson, Hope A. (1997). Thinking professionals: teaching critical cataloging. Technical Services Quarterly, 15(1-2), 51-66. https://doi.org/10.1300/J124v15n01_06

Omekwu, C. O., \& Eteng, U. (2006). Roadmap to change: emerging roles for information professionals. Library Review, 55(4), 267-277. https://doi.org/10.1108/00242530610660816

Pedagogy. (2019). In Oxford English Dictionary. Retrieved March 2, 2019, from https://www.oed.com/

Riva, P., Bœuf, P., \& Žumer, M. (2017). IFLA Library Reference Model, a conceptual model for bibliographic information. Retrieved from https://www.ifla.org/files/assets/cataloguing/frbr-lrm/ifla-lrm-august-2017_rev201712.pdf

Rousidis, D., Garoufallou, E., Balatsoukas, P., \& Sicilia, M.-A. (2015). Evaluation of metadata in research data repositories: the case of the dc.subject element. In Garoufallou E., Hartley R., Gaitanou P. (Eds.), Metadata and Semantics Research. MTSR 2015. Communications in Computer and Information Science, vol. 544 (pp. 203-213). Springer, Cham.

Saumure, K., \& Shiri, A. (2008). Knowledge organization trends in library and information studies: a preliminary comparison of the pre- and post-web eras. Journal of Information Science, 34(5), 651-666. https://doi.org/10.1177/0165551507084300

Theory, n. (2019). In Oxford English Dictionary. Retrieved March 2, 2019, from https://wwwoed-com.eres.library.manoa.hawaii.edu/view/Entry/200431?redirectedFrom=Theory\#eid

\footnotetext{
About the authors

Suzhen Chen is a Chinese Language Cataloging/Metadata Librarian at the University of Hawai' $i$ at Mānoa. She obtained a master's degree in Library and Information Science from the University of Illinois at Urbana-Champaign in 2009.

Margaret Joyce has been the Hawaiian Materials Cataloging/Metadata Librarian at the University of Hawaii at Manoa since 2017. She received her MLIS at the University of Illinois, with a certificate in Special Collections. She previously worked for several years as an English as a foreign language teacher.
} 